\title{
Urban Environment Problems Related to Climate Change and Improvement Strategies in Large Cities-the Case of Shenzhen, China
}

\author{
Hongyan Li, Jia Yu \\ Email address: \\ lihy04@126.com (Hongyan Li), 1152715229@qq.com (Jia Yu)
}

Department of Architecture, Faculty of Human Settlement and Civil Engineering, Xi'an Jiao-tong University, Xi'an, Shaanxi, China

\section{To cite this article:}

Hongyan Li, Jia Yu. Urban Environment Problems Related to Climate Change and Improvement Strategies in Large Cities - the Case of Shenzhen, China. International Journal of Environmental Protection and Policy. Vol. 4, No. 3, 2016, pp. 86-92. doi: 10.11648/j.ijepp.20160403.16

Received: March 10, 2016; Accepted: April 15, 2016; Published: May 24, 2016

\begin{abstract}
In modern society, the environmental issues have played an increasingly crucial role in the development of a city, along with the accelerating velocity of development and the extension of scale. City climate is closely related to city planning. Meanwhile city planning should take fully consideration on the issue of climate in order to support sustainable development of a city and the ecological city construction. This paper takes Shenzhen, which is representative of modern cities of China, as an example to analyze current situation and characteristics of the climatic environment in big cities with rapid developing process. The aim is to find out the problems gradually appearing in the rapid growth, particularly environmental pollution and severe urban heat island effect. By analyzing its causes and solving those problems with the help of urban planning, we hope fast growing cities can develop in a more rational way.
\end{abstract}

Keywords: Environment Problems, Climate Change, Improvements Measures

\section{Introduction}

Climate, as an important part of the natural environment for human survival, its any changes will bring serious impact and harm to human society. But in recent years, great climate changes have happened due to the impact of human activities, which also led to a series of environmental problems such as air pollution, greenhouse effect, heat island effect, etc. Thus, rational urban planning can be taken as a very effective method to alleviate the urban environmental problems. Learn to analyze the law of urban climate and environment and scientifically plan functional distribution, road system, green settings especially in those rapidly growing cities such as Shenzhen, which can greatly improve the quality of living environment and promote urban benign development.

\section{General Situation of the Case Study Area}

\subsection{Geographical Location of Shenzhen}

Shenzhen city, also known as "Pengcheng", is located in the southern China, adjacent to Hong Kong. Actually, Shenzhen is located in the southern coast of Guangdong Province, east of the Daya Bay, west to Lingdingyang of Pearl River Estuary, south to Shenzhen River and Hong Kong, north to the city of Dongguan and Huizhou city (Figure 1).
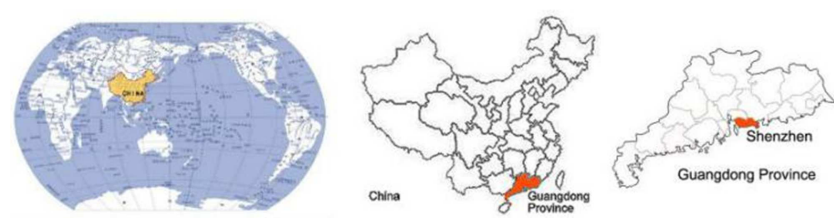

Figure 1. Geographical location of Shenzhen.

\subsection{Development Background of Shenzhen}

As the saying goes, "ten years of China to see Shenzhen", although economic development history of Shenzhen only has 30 years, there has been 6700 years of human activities and urban history of Shenzhen started from the year of 1673. Shenzhen is a city of immigrants in China, so immigrant population grows rapidly, and the language and culture is complex and diverse. As China's first special economic zone, 
Shenzhen created the "Shenzhen speed" (Figure 2). The Chinese government considered it as the "experimental field" of the reform and window to show its achievement. Shenzhen is located in the front of the Pearl River delta, which made it bridge of HongKong and China. Besides, it is the important transport hub of Southern China coastal region, the window of China's high-tech achievements on transferring and trading, and distribution center of electronic, watches, furniture, agricultural products and many other national patented products.
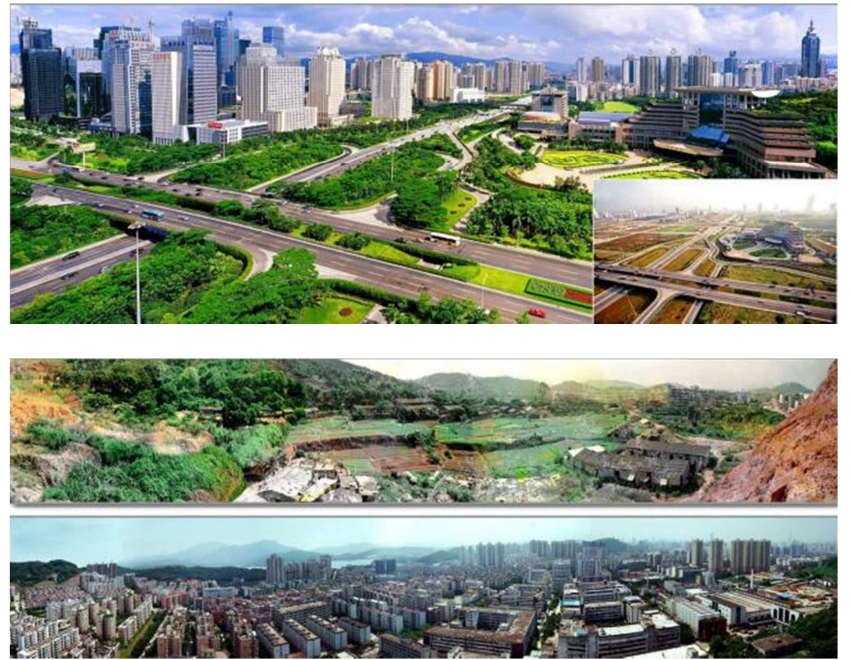

Figure 2. Contrast of before and after development in Shenzhen.

\subsection{Spatial Structure of Shenzhen and Its Planning Design}

\subsubsection{Urban Scale}

Shenzhen has a total of six administrative regions and four functional areas (Figure 3). Shenzhen has experienced a rapid urbanization process in the past 30 years. At present, more than 13 million people have gathered on less than $2000 \mathrm{~km}^{2}$ land in Shenzhen [1]. In this urban environment, public service is under tremendous pressure and urban transportation, education, and entertainment facilities are overloaded [2]. Under this circumstance, the government tries to control the population growth and build high-rise buildings to ease the lack of urban land. Therefore, high density of building skyscrapers has become a distinctive feature of Shenzhen.

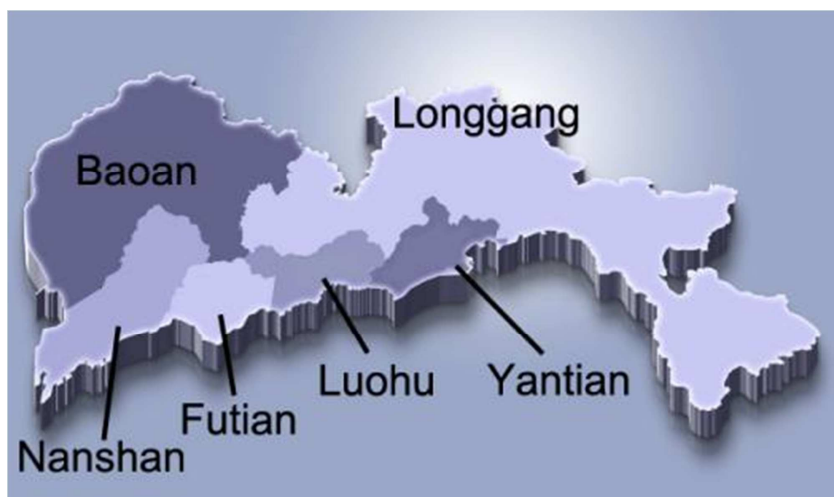

Figure 3. Six administrative regions of Shenzhen.

\subsubsection{Overall Layout Features of the City}

The development of urbanization in Shenzhen is zonal distribution based on the topography of the terrain. The built-up areas are divided into four categories: urban centers, sub urban centers, urban group centers, and non-urban centers [3] (Figure 4). The multi core structure of the city center and the group layout are the main characteristics of Shenzhen. Each group has the function of industry, living space and business activities. Different groups are divided by green barriers and connected by rapid transit. Groups have different functions. Some focus on production, some focus on the ecology, and some focus on comprehensive functions [4].

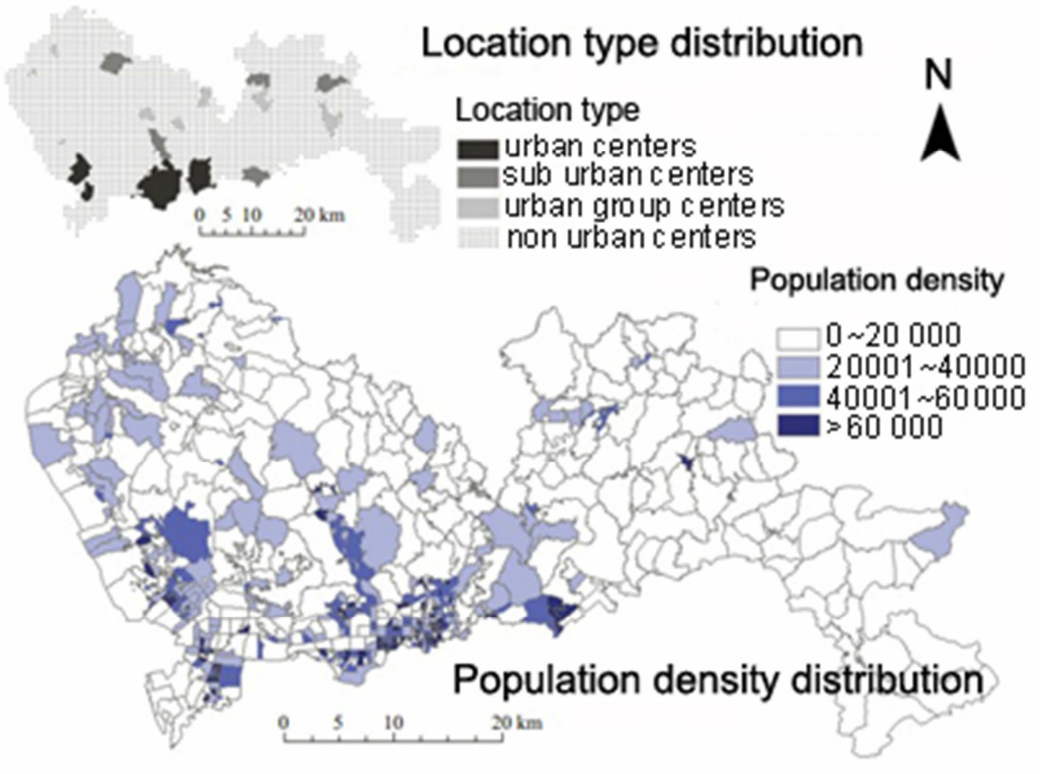

(Source: Reference [3])

Figure 4. Population density in Shenzhen. 


\subsection{Current Situation of Urban Climate in Shenzhen ${ }^{i}$}

In recent years, the climate of Shenzhen has gradually changed with a rising temperature, increased precipitation intensity, and decreased sunshine, humidity and visibility, accompanied by global warming and the rapid development of Shenzhen.

\subsubsection{Temperature}

Shenzhen is located in the coastal area of Southern China,

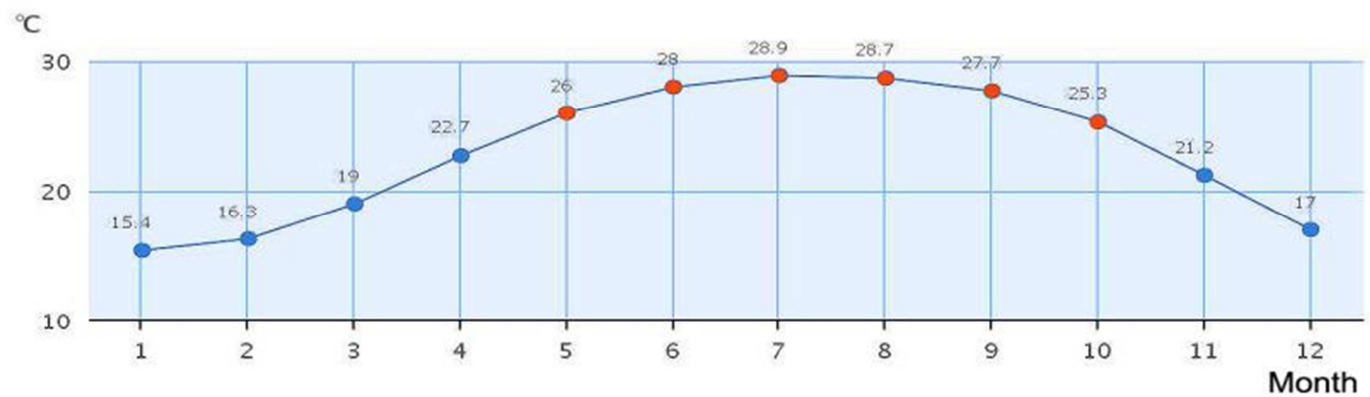

(Source: Meteorological Bureau of Shenzhen Municipality)

Figure 5. The monthly average temperature from 1981 to 2010 in Shenzhen.

The temperature change map of Shenzhen from 1954 to 2005 (Figure 6) shows that although the temperature of Shenzhen has a certain degree of fluctuation, it is relatively stable in 1980 and rises obviously after 1980 in general [5]. The temperature rose 1.5 degrees in less than 20 years, which shows that the temperature changes in Shenzhen are still worth great attention.

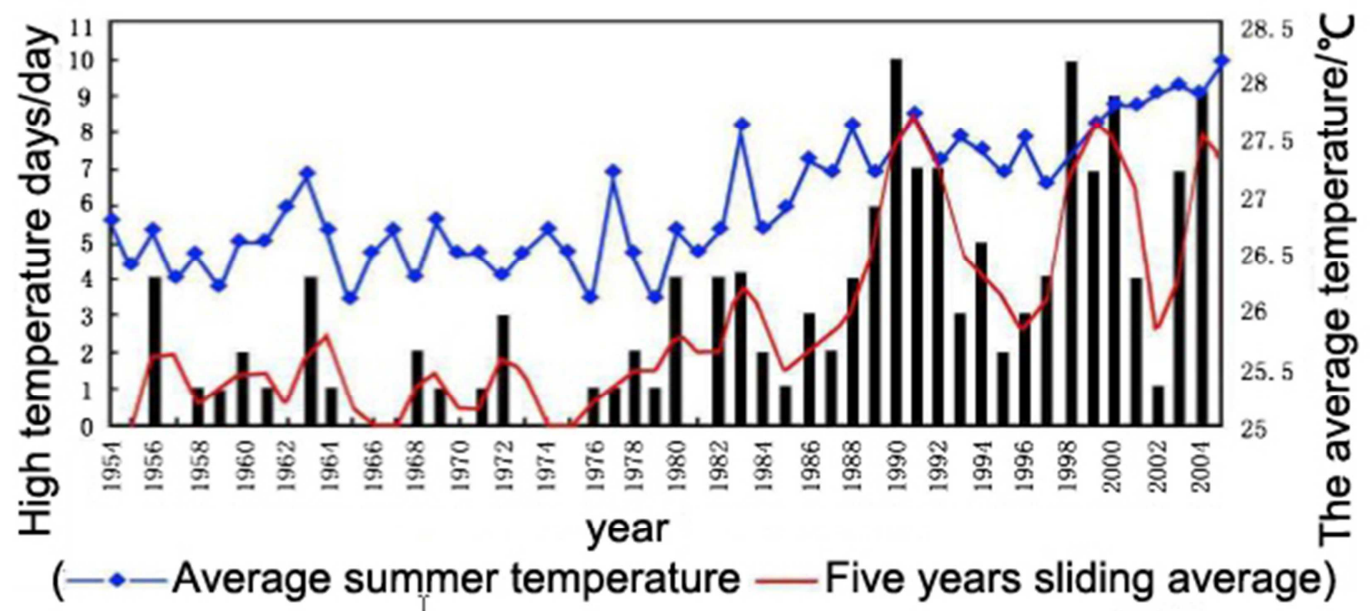

(Source: Reference [5])

Figure 6. Temperature change in Shenzhen (1954-2005).

The terrain of southeast Shenzhen is high and northwest is low. Land form is mainly low mountain and gentle terrace and terrace hills. It is coastal plain in western and plain accounted for $22.1 \%$ of the total land area. Due to the different terrain, different distance to the coastline and the different influence of oceans moderate, the high temperature space distribution has the obvious regionalism, decreasing from north to South. The temperature in south is lower than it in the north, and the high temperature center is in the north. Entering the 1990s, as the climate becomes warmer and the urban develops, not only the days of high temperature increased, but also the duration and intensity of high temperature increased.

\subsubsection{Wind}

Shenzhen is mainly influenced by the weather system of middle and high latitudes. The prevailing wind direction in a year is south-east, and followed by northeast. The annual average wind speed is 2.1 meters per second in 2013, the average wind speed of the first and fourth quarter is the largest and the wind speed in summer is the smallest. 


\subsubsection{Humidity}

The average relative humidity in Shenzhen was $74 \%$ in recent five years and there are April to August that the average relative humidity can reach $79 \%$ to $81 \%$. The minimum humidity was $61 \%$ in December. The humidity is much less than that before the late $1980_{\mathrm{S}}$.

\subsubsection{Rainfall}

Shenzhen is rich in rainfall and the annual average rainfall days are 128 days in recent five years. Influenced by monsoon, seasonal drought and flood are obvious in Shenzhen: April to September is the rainy season, and the rest of the time is the dry season. The annual variation of rainfall is large, and it is a single peak in each month of the year with the maximum in August and minimum in January. (Source from Meteorological Bureau of Shenzhen Municipality)

\section{Improvement of Urban Planning and Measures for Urban Heat Island Effect in Shenzhen}

\subsection{Causes of Urban Heat Island Effect}

Urban heat island effect refers to the phenomenon that the temperature in city is significantly higher than that in the outer suburbs because of high heat storage such as much artificial fever, buildings and roads, etc. and green space reduction and other factors (Figure 7). In the near surface temperature map, the change of temperature in the suburbs is very small, while urban areas is a high temperature region, like a prominent sea island, so it is called the urban heat island.

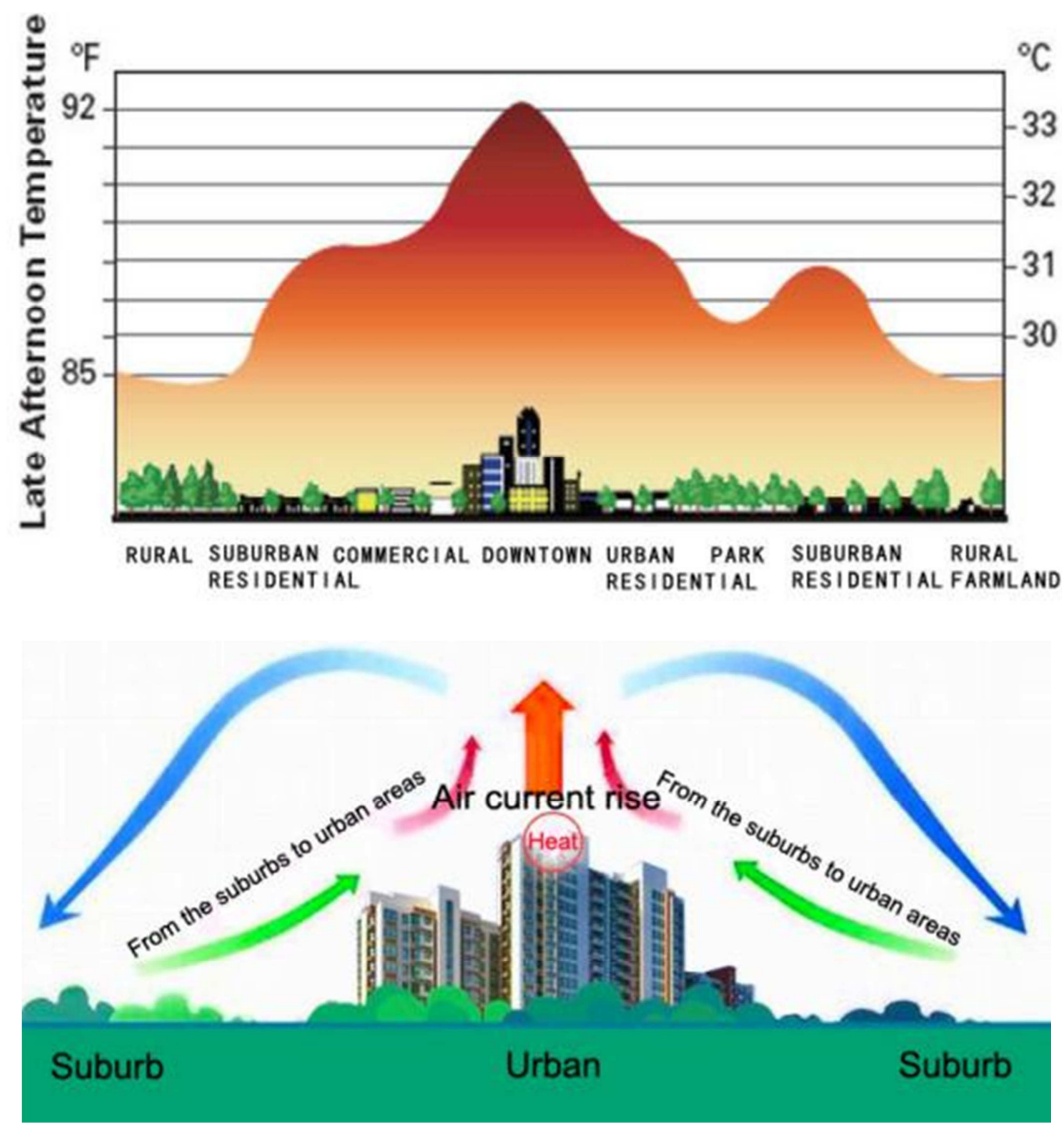

Figure 7. Formation and performance of urban heat island effect.

The main reasons for the formation of urban heat island effect are as followings:

(1) There are a large number of energy consuming devices such as boilers, heaters etc. and a variety of motor vehicles in the city. These machines and human life activities consume a lot of energy, most of which discharge to the urban air space in the form of heat (Figure 8).

(2) A large number of urban buildings and roads consists of brick, cement and asphalt materials form urban cushion layer, which have more heat capacity, thermal conductivity but low reflectivity of solar light and large absorption rate than in suburban [6]. Therefore, the temperature of cushion layer in urban is much higher than the air temperature during the day. In the night, the city surface layer's long wave radiation always rise the atmospheric temperature near surface. Moreover, due to the poor water retention of cushion layer, the water evaporation dissipates less heat. As a consequence, the city has large latent heat and the temperature is also high correspondingly.

(3) The dense urban buildings and interlaced roads and bridges form rough cushion layer in city, which increases wind resistance, causes lower wind speed and heat dissipates not easily (Figure 9).

(4) Air pollution in the city makes the urban air quality 
decline and the content of some substances (such as smoke and dust, $\mathrm{SO}_{2}, \mathrm{NO}_{\mathrm{X}}, \mathrm{CO}$ ) increase, which are good absorption of infrared radiation. This has led to the city atmosphere absorbs more infrared radiation and the temperature become higher.

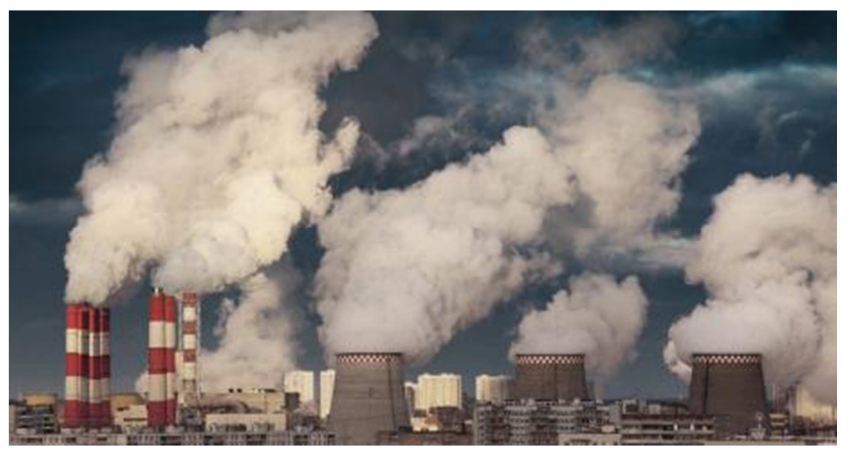

Figure 8. Hot exhaust gas is directly discharged into the air.

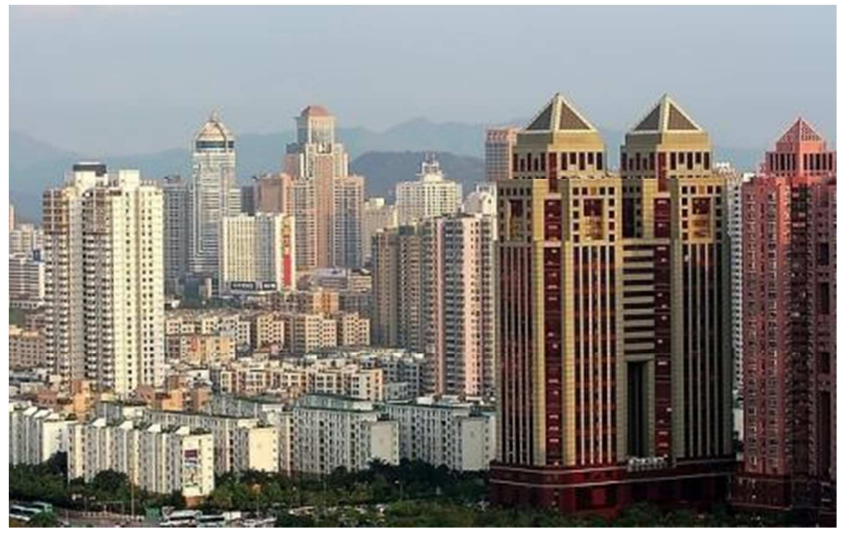

Figure 9. Dense buildings affect urban ventilation.

\subsection{Current Situation of Heat Island Effect in Shenzhen}

Although Shenzhen is in the southern coastal area, there is also a high temperature, which shows that the urban heat island effect contributes greatly to the emergence of high temperature zone in urban area with high buildings and dense population. In general, spatial distribution of urban heat island intensity in Shenzhen shows that "strong in the center, moderate in the west and weak in the east" in 2011 [1] (Figure $10,11)$.

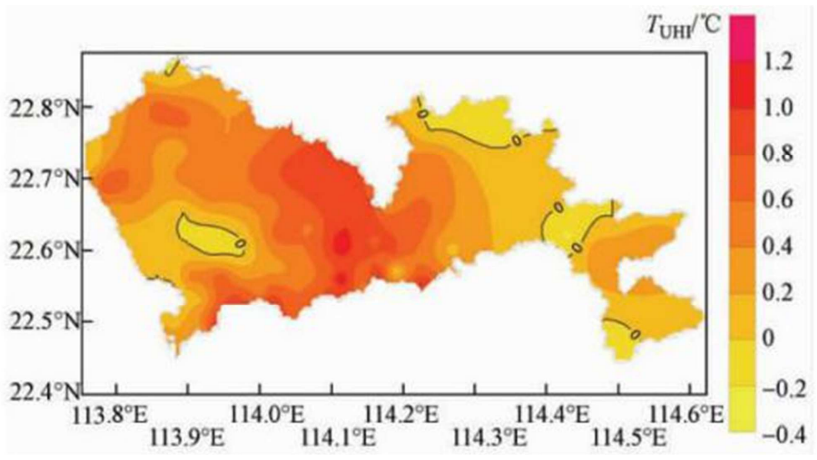

(Source: Reference [1])

Figure 10. Distribution of urban heat island in Shenzhen in 2011.

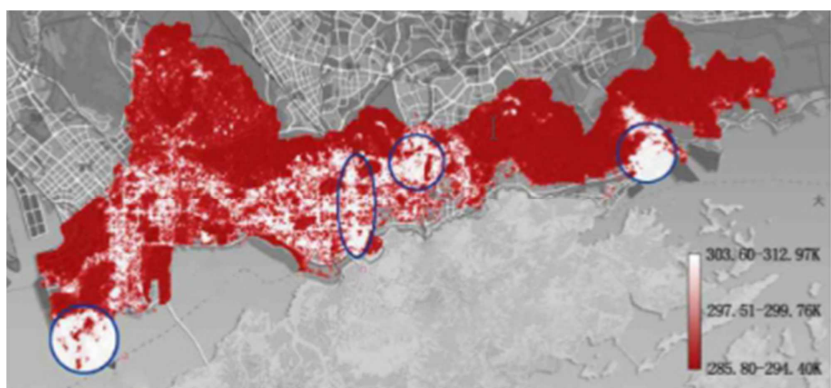

Figure 11. The more light color, the heat island effect is stronger.

Actually, the land-sea distribution is the major factor affecting the space distribution of heat island intensity in Shenzhen [7]. The climate regulation of the ocean makes the heat island intensity relatively low in east and west sides of Shenzhen, while the central area becomes the center of the urban heat island for its south is HongKong land, which has weak ocean adjustment (Figure 12).

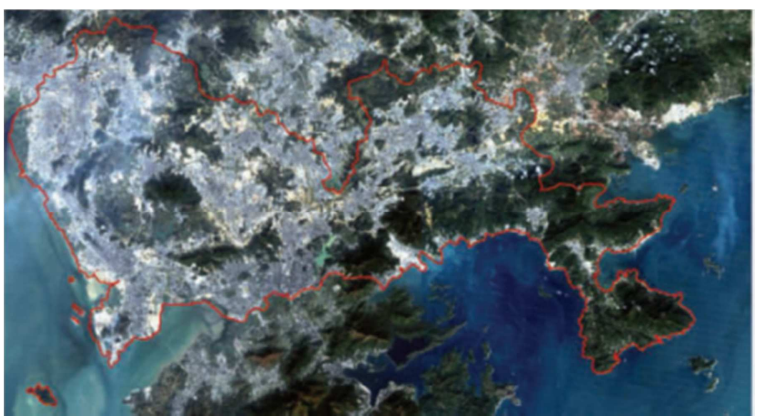

Figure 12. The land-sea distribution map of Shenzhen.

\subsection{Negative Impacts of Heat Island Effect}

Under the influence of heat island effect, clouds and fog increase, and causes harmful gas and dust accumulation, affects the distribution of air pollutants above the urban area and forms serious air pollution. Besides, it also makes the quality of urban environment deteriorate and trigger many human diseases.

In addition, the urban heat island effect makes the average annual air temperature in the city higher than it in the suburbs for approximately 1 centigrade and even more [8]. Besides, the dense and high buildings in the city hinder the air circulation and decrease the wind speed, which are not beneficial to ventilation and heat dissipation. Moreover, high temperature is not only unsuitable for living and will increase the cooling energy consumption. As a matter of fact, the heat island effect is a kind of phenomenon due to micro climate change causing by the temperature rise on urban surface, which is the most obvious in night and winter and is also one of the most obvious characteristics of the climate in Shenzhen.

\subsection{Some Planning and Design Measures for Shenzhen Heat Island Effect}

Long term strategies should be considered in the urban planning to ease heat island effect. The following are some suggestions: 
First of all, strengthen the control of urban population and the scale of construction.

Besides that, strengthen the control of building layout, shape and arrangement of green plants (Figure 13), besides, reasonably design the natural ventilation in urban area and strengthen the construction of urban ventilation corridors considering the urban wind direction (Figure 14).

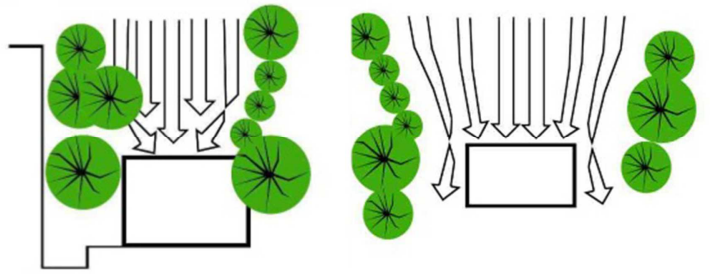

Figure 13. Influence of plant arrangement on the ventilation.

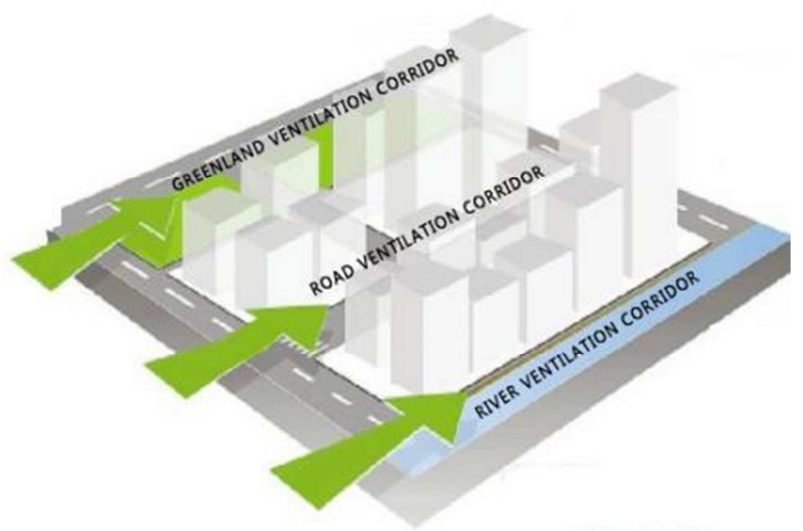

Figure 14. Three kinds of urban wind corridor.

Next, adjust the layout of the city in the urban functional zoning, arrange and migrate the large row heat production enterprises to the suburbs [9].

In addition, explore energy saving and emission reduction architectural design methods, and promote the development of green ecological architecture (Figure 15).

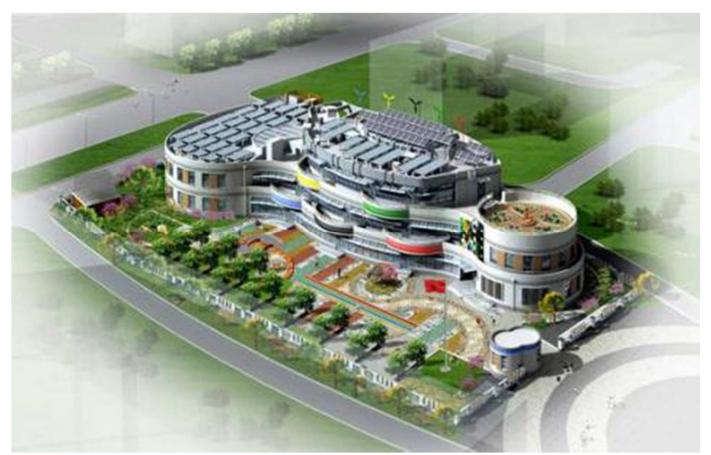

Figure 15. Green ecological architecture.

Then, develop green transportation. Reconsider the use ratio of vehicle road system in the urban land, implement the development model of public transport through the optimization of the transport structure, and vigorously carry out the construction of slow traffic system and green road planning, promoting low-carbon and carbon reduction (Figure 16).

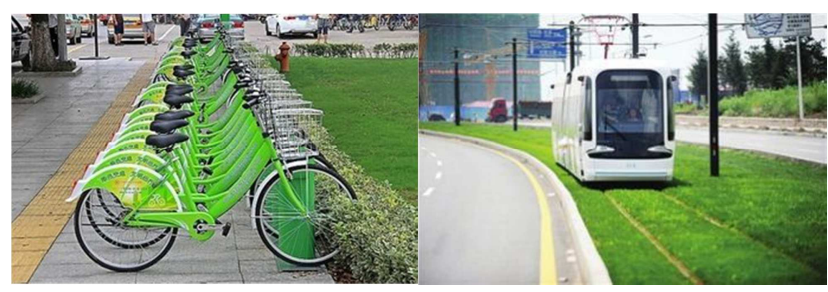

Figure 16. Green transportation--public bicycle and traffic system.

Apart from that, enterprises in Shenzhen should continue to develop the efficient and environment friendly natural gas as well as other green energy and reduce the heat emitted by the burning of energy.

Moreover, increase the city green quantity and pay more attention to the vertical greening. From the ecological benefits, the low-key cement roof and wall store light and heat during the day while release them at night, which not only makes summer hotter but also not conducive to view. There are materials show that the temperature of wall surface with vertical greening is lower than that of the red brick for $5.5-14^{\circ} \mathrm{C}$ and also greatly reduce the thermal radiation of the wall [10]. Green plants can produce cooling effect through the absorption and the consumption of water, reduce greenhouse through photosynthesis to absorb lots of carbon dioxide in the air and inhibit warming effect through retention of the dust in the air. Therefore, develop urban vertical greening (Figure 17), improve green space utilization ratio, build roof garden (Figure 18) and create green walls, form floor-wall-roof multi-level landscape ecological system are key measures to improve the urban heat island effect.

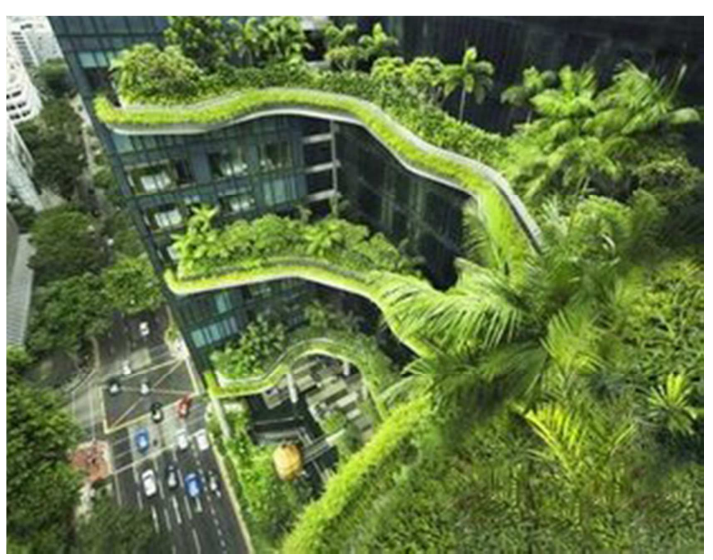

Figure 17. Vertical greening.

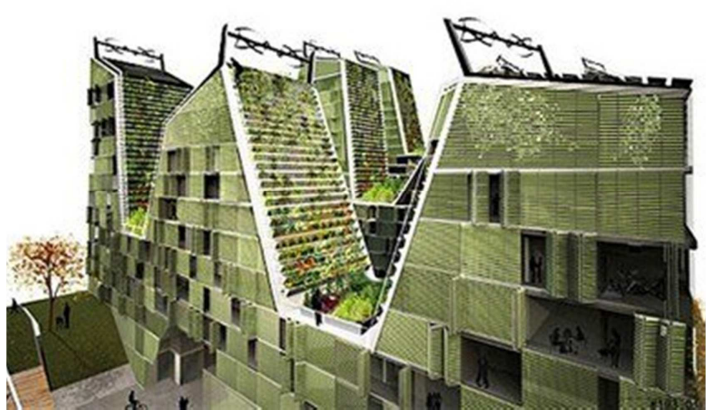

Figure 18. Roof garden. 
Furthermore, encourage low impact development, such as pavement infiltration, vegetation, biological retention and other technology [11] (Figure 19).

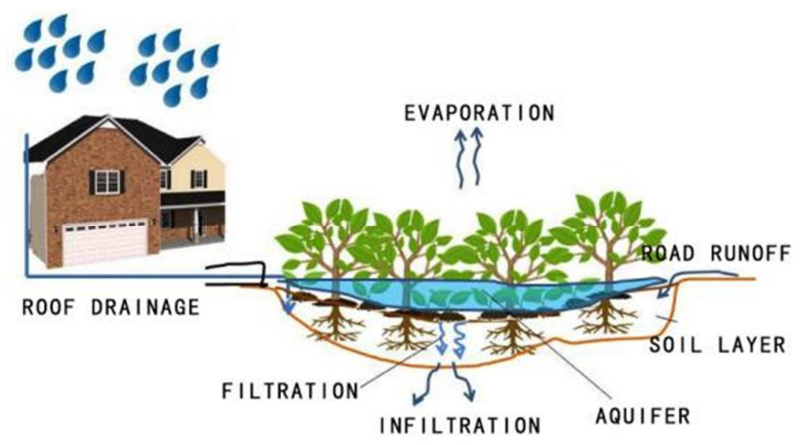

Figure 19. Low impact development.

Last but not least, expand the scale of urban external space and enhance landscape design. Urban external space mainly refers to park, square, green belt, grass, lakes, water, etc.

\section{Conclusion}

In modern society with rapid urban development, when people enjoy modern material civilization, they are also feeling the crisis of ecological environment. We should no longer take GDP as the sole measurement of success. It is significant to focus more on resource consumption, social justice and human development and other issues in the economic development, instead of pursuing the size, speed and GDP growth. Reasonable and effective urban planning should be based on the study of urban environment and guide the transformation of urban development, meanwhile we should pay attention to the status and role of climate and environment design in urban planning, consider the rational use of urban climate resources, attach importance to improvement of green space and water surface to improve urban problems in the rapid development process and create a healthy living space for people.

\section{Acknowledgements}

This work was financially supported by "The National Key Technology R\&D Program" (2012BAJ15B06).

\section{References}

[1] Lei Li, Lijie Zhang, Xiaoli zhang: Impacts of Geographic Feature, Population Distribution and Power Load on the Urban Heat Island in Shenzhen Metropolis. Acta Scientiae Circumstantiae, vol. 32 (2012), pp. 66-70, in Chinese

[2] Hui Xu: Evolution of the Urban Spatial Structure of Shenzhen. Art Education, vol. 6 (2013), in Chinese

[3] Yanping Chen, Yan Song, Yi Zhang: Impact of Land Use Development on Travel Mode Choice. A Case Study in Shenzhen. Urban Transport of China, vol. 9 (2011), pp. 80-82, in Chinese

[4] Jianwei Tan: Group Layout is the Biggest Feature of Shenzhen City. Shenzhen Special Zone Daily, vol. 6 (2011), in Chinese

[5] Chunyan Zeng, Yin Jiang, Xiangming Sun: Characteristics and Situation of High Temperature Weather in Summer in Shenzhen. Meteorological Science and Technology, vol.35 (2007), pp. 191-197, in Chinese

[6] Zhiqiang Zhen, Feng Cao: The Influence of the Urban Cushion Layer on Physical Environment of Buildings. Shanxi Architecture, vol. 21 (2007), pp. 203-204, in Chinese

[7] Changguang Wu, Lili Xia, Yaoyu Lin: Thermal Environment Characteristics of the Typical Residential Areas in Shenzhen City and Its Influencing Factors Analysis. Journal of Harbin Institute of Technology, vol. 6 (2015), pp. 59-62, in Chinese

[8] Jingna Song: Discussion of Urban Heat Island Effect. Theoretical Research on the Urban Construction, vol. 16 (2015), in Chinese

[9] Xiguang Hu: Application of Urban Planning in Response to the Urban Heat Island Effect. New West, vol. 4 (2015), pp. 62-62, in Chinese

[10] Tang Man: Improve the Thermal Environment of the Buildings by Greening Measures, vol. 21 (2015), pp. 198-198, in Chinese

[11] Nian Ding, Aibing Hu, Xinxin Ren: The Application Status and Prospect of Low Impact Development model in Shenzhen. Water Supply and Drainage, vol. 11 (2012), pp. 141-144, in Chinese

i Note: The basic data in this part come from Meteorological Bureau of Shenzhen Municipality and the data used in this part were recalculated by the authors based on the basic data. 